Research Article

\title{
Knowledge and Attitude towards Covid-19 among Healthcare Workers of A Tertiary Care Hospital in India.
}

\author{
Alok Dixit ${ }^{1 *}$, Amit Vikram Singh ${ }^{1}$, Chandra Veer Singh ${ }^{1}$, Ramakant Yadav ${ }^{2}$, Sandeep Kumar Singh ${ }^{3}$ \\ Department of ${ }^{1}$ Pharmacology and ${ }^{2}$ Neurology, U P University of Medical Sciences, Saifai, Etawah. UP 206130. and ${ }^{3}$ Research \\ Scientist, GenTox Research and Development, Lucknow. UP 226001, India. \\ *Corresponding author's E-mail: alkdxt@yahoo.co.in
}

Received: 24-03-2021; Revised: 21-05-2021; Accepted: 28-05-2021; Published on: 15-06-2021.

\section{ABSTRACT}

ICOVID-19 has involved serious occupational health risk to the health care professionals who are frequently exposed to infected individuals. Knowledge and attitude among health care professionals can prevent the spread of COVID-19. The present study was aimed to identify the current status of knowledge and attitude regarding COVID-19 among healthcare professionals in a tertiary care hospital. A questionnaire-based cross-sectional study was conducted among medical staff (doctors, nurses and lab technicians) in a tertiary care hospital to assess the knowledge and attitude toward COVID-19 among healthcare workers. The questionnaire comprised of three sections (demographic, knowledge and attitude) for data collections. Non parametric tests and Pearson correlation was used to analyze data using $\mathrm{R}$ (The comprehensive $\mathrm{R}$ archive network) version 3.6.2. Of the 117 respondents, $46.15 \%$ were doctors, $25.64 \%$ nurses and $28.20 \%$ technical staff. On data analysis, $94 \%$ were in good knowledge category, $6 \%$ had poor knowledge and $100 \%$ had positive attitude. In the knowledge section, median value for doctors was higher than nurses and technical staff $(P=0.02)$. Doctors showed higher median values for attitude than nurses and technical staffs $(P=0.02)$. A weak positive correlation, $r(115)=.20, p=$ .0299 was evidenced between knowledge and attitude for COVID-19. Present study shows that the health care workers of a tertiary care institute had good knowledge and positive attitude towards COVID -19, though in some areas the knowledge and attitude was observed low. The study also observes that there is need for continuous teaching and training programs.

Keywords: COVID-19, healthcare workers, knowledge, attitude, tertiary care hospital.

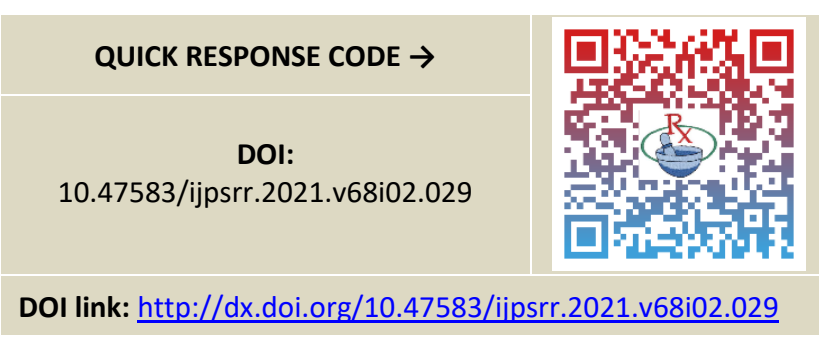

\section{INTRODUCTION}

C orona virus disease 2019 (COVID- 19), an illness caused by a novel corona virus or severe acute respiratory syndrome 2 (SARS-CoV-2) was initially identified as a pneumonia of unknown aetiology in Wuhan city, Hubei Province, China. It was reported to the World Health Organization on 31 December 2019 and on January 30, 2020, COVID-19 outbreak was declared a global health emergency. ${ }^{1}$ COVID-19 transmits from person to person by droplets of an infected person on sneezing and coughing or by coming in direct contact with surface and has an incubation period of 4-14 days. The predominant clinical feature of COVID-19 are fever, dry cough, dyspnea, myalgia, fatigue, evidence of pneumonia on radiograph and severe systemic conditions leading to complications such as acute respiratory distress syndrome (ARDS), arrhythmia, shock, acute cardiac injury, secondary infection, acute kidney injury and sometimes death may occur in severe cases. ${ }^{2}$ Elderly patients or who had chronic medical conditions like diabetes mellitus and cardiovascular disease are more likely to get severe infection. Currently, there are no vaccines against the infection or any proven therapeutic options which can improve the outcome in patients of confirmed COVID-19 and mostly the treatment is symptomatic. ${ }^{3}$

All health care workers like doctors, nursing staff, pharmacist, laboratory technicians, paramedics and interns are primarily involved with COVID-19 patient's care and symptomatic management. COVID-19 has involved serious occupational health risk to the health care professionals who are frequently exposed to infected individuals. ${ }^{4}$ Healthcare professionals ( $\mathrm{HCF}^{\prime} \mathrm{s}$ ) are regularly in contact with COVID-19 patients and there is great possibility of them getting infected despite using (PPEs) personal protective equipments; thus, health care professionals are expected to be at high risk of infection. The protection of HCF's and prevention of intra-hospital transmission of infection are an important aspects in any epidemic response and health care professionals are required to have updated knowledge regarding source, transmission, symptoms and preventive measures. ${ }^{5}$ Lack of adequate knowledge among health care professionals has been observed to cause delayed diagnosis, rapid spread of disease and poor infection control. ${ }^{\text {SStudies in }}$ past have explored the attitude and knowledge of HCWs toward prevailing infectious disease epidemics, their keenness and fear toward work during the epidemics. In previous recent epidemic of MERS it was observed that in spite of having good knowledge and positive attitude towards MERS there were some areas where poor 
knowledge and adverse attitude of HCWs was observed. ${ }^{7}$ In another study of MERS-COV it was seen that there are knowledge gap and negative attitude among healthcare providers at Makkah hospitals towards MERS- CoV infection. ${ }^{8}$ Based on above studies we had a keen interest and enthusiasm to evaluate knowledge and attitude of health care workers in our tertiary care hospital and teaching institute during COVID- 19.Good knowledge and attitude among health care professionals can prevent the spread of COVID-19. Therefore, the present study was aimed to identify the current status of knowledge and attitude regarding COVID-19 among healthcare professionals in a tertiary care hospital. The study may provide insight into the corrective measures required to improve knowledge and attitude as good human health behaviour are preceded by good knowledge and attitude.

\section{MATERIAL AND METHODS}

A questionnaire-based cross-sectional study was conducted among 117 medical staff (54 doctors, 30 nurses and 33 lab technicians) in UP University of Medical Sciences, Saifai to assess the knowledge and attitude toward COVID-19 among healthcare workers. A prevalidated questionnaire from previous study was modified to adjust for current settings of the institute. The study was planned after getting approval from Institutional Ethical Committee and a written informed consent was obtained from all the participants. The questionnaire consisted of two separate sections for knowledge and attitude towards COVID- 19. First section consisted of questions related to knowledge about COVID-19 which had response yes and no and were considered as point descriptors. Second section consisted of questions evaluating attitude of healthcare workers towards COVID-19.Thetotal knowledge score varies between 0 (with no correct answer) and 18 (for all correct answers), and a cut off level of $<15$ was evaluated as poor knowledge, and $\geq 15$ indicated good knowledge. For the question on attitude the responses were based on 5 points Likert scale with score of 1 to 5 ranging from strongly agree to strongly disagree. A score of $\leq 2$ (answering for strongly agree and agree) was considered positive attitude and a score of 3 to 5 indicated a negative attitude (answering undecided, disagree or strongly disagree).

Data was analysed using $R$ (The comprehensive $R$ archive network) version 3.6.2. ANOVA was used to examine the knowledge and attitude differences between doctor, nurses and technical staff. Shapiro-Wilk test was used to check the distribution of residuals and Levene's test was performed to examine the homogeneity of variance. Kruskal-Wallis test was performed as non-parametric approach and Wilcoxon rank sum test was used to perform pairwise comparisons as a post-hoc approach to identify the significantly different groups. Results were adjusted for multiple comparisons using Benjamini-Hochberg (BH) adjustment as false discovery rate. Pearson correlation coefficient was used to observe correlation between knowledge and attitude. A P value of $<0.05$ was considered significant.

\section{RESULTS}

A total of 117 respondents were included in analysis, of which $46.15 \%(n=54)$ were doctors, $25.64 \%(n=30)$ nurses and $28.20 \%(n=33)$ technical staff (laboratory technicians). The mean age of all participants (doctors, nurses and technical staff) was $36 \pm 5.18$ years (mean \pm SD) as shown in Table 1.

Table 1: Demographic characteristic of health care workers

\begin{tabular}{|c|c|c|c|}
\hline Variables & Doctors $(\mathbf{n = 5 4}$ & Nurses $(\mathbf{n = 3 0 )}$ & Technical staff $(\mathbf{n}=\mathbf{3 3})$ \\
\hline Mean Age & 32 & 38 & 40 \\
\hline $\begin{array}{c}\text { Sex: } \\
\text { Male } \\
\text { Female }\end{array}$ & $32(59 \%)$ & $9(30 \%)$ & $33(100 \%)$ \\
\hline $\begin{array}{c}\text { Source of CoVID-19 } \\
\text { information } \\
\text { Television }\end{array}$ & $22(40.7 \%)$ & $21(70 \%)$ & $4(12 \%)$ \\
\hline $\begin{array}{c}\text { Social media } \\
\text { Websites of hospital }\end{array}$ & $12(22 \%)$ & $8(27 \%)$ & $26(79 \%)$ \\
\hline $\begin{array}{c}\text { Friends, relatives } \\
\text { Unheard }\end{array}$ & $34(63 \%)$ & $20(67 \%)$ & $3(9 \%)$ \\
\hline
\end{tabular}

All the respondents correctly answered that COVID-19 is a viral infection, transmitted by close contact with the infected person and the possible symptoms are fever, cough, sore throats and shortness breath. The response that antibiotics are the first-line treatment was given by 7 doctors (13\%), 8 nurses (27\%) and 10 technical staff (30\%). Only $20 \%$ nurses and $27 \%$ technical staff agreed that patients with underlying chronic disease are at higher risk of infection and death, while all doctors agreed with above statement. Doctors and nurses agreed in equal manner (100\%) that healthcare workers are at a higher risk of infection however, only technical staff (21\%) disagreed with above view. On the question about family members of COVID-19 patients be isolated most of the responders like doctors $8(15 \%)$, nurses $6(20 \%)$ and technical staff $8(24 \%)$ answered incorrectly. Some of the responders like 
doctors 5 (9\%), nurses 5 (17\%) and technical staff 7 (21\%) answered incorrectly that $1 \%$ sodium hypochlorite solution is not suitable for sanitization in COVID-19. The question asked whether awareness of bio medical waste is adequate, doctors 7 (13\%) and technical staff 4 (12\%) replied that it is inadequate, though answers by all nurses reflected adequate awareness. All questions related to knowledge of health care workers towards COVID- 19 have been evaluated in Table 2 .

Table 2: Knowledge of healthcare workers toward COVID-19

\begin{tabular}{|c|c|c|c|c|c|}
\hline S. No & Questions & $\begin{array}{l}\text { Response provided } \\
\text { by participants }\end{array}$ & Doctors & Nurses & Technical staff \\
\hline 1 & COVID-19 is a virus infection & Yes & $54(100 \%)$ & $30(100 \%)$ & $33(100 \%)$ \\
\hline 2 & $\begin{array}{l}\text { COVID-19 is transmitted by close contact } \\
\text { with the infected person }\end{array}$ & Yes & $54(100 \%)$ & $30(100 \%)$ & $33(100 \%)$ \\
\hline 3 & $\begin{array}{l}\text { Fever, cough, sore throats and shortness } \\
\text { breath are possible symptoms of COVID-19 }\end{array}$ & Yes & $54(100 \%)$ & $30(100 \%)$ & $33(100 \%)$ \\
\hline 4 & The isolation period is 2 weeks. & Yes & $54(100 \%)$ & $30(100 \%)$ & $33(100 \%)$ \\
\hline 5 & Antibiotics are the first-line treatment & No & $7(13 \%)$ & $8(27 \%)$ & $10(30 \%)$ \\
\hline 6 & COVID-19 vaccine is available in markets & No & $54(100 \%)$ & $30(100 \%)$ & $33(100 \%)$ \\
\hline 7 & $\begin{array}{l}\text { Patients with underlying chronic diseases } \\
\text { are at a higher risk of infection and death }\end{array}$ & Yes & $54(100 \%)$ & $6(20 \%)$ & $9(27 \%)$ \\
\hline 8 & $\begin{array}{l}\text { Healthcare workers are at a higher risk of } \\
\text { infection }\end{array}$ & Yes & $54(100 \%)$ & $30(100 \%)$ & $7(21 \%)$ \\
\hline 9 & COVID-19 could be fatal & Yes & $54(100 \%)$ & $30(100 \%)$ & $33(100 \%)$ \\
\hline 10 & $\begin{array}{l}\text { Suspected COVID-19 patients should be } \\
\text { quarantined }\end{array}$ & Yes & $54(100 \%)$ & $30(100 \%)$ & $33(100 \%)$ \\
\hline 11 & $\begin{array}{l}\text { COVID-19 positive patients should be } \\
\text { isolated }\end{array}$ & Yes & $54(100 \%)$ & $30(100 \%)$ & $33(100 \%)$ \\
\hline 12 & $\begin{array}{l}\text { Family members of COVID-19 patients be } \\
\text { isolated }\end{array}$ & No & $8(15 \%)$ & $6(20 \%)$ & $8(24 \%)$ \\
\hline 13 & $\begin{array}{l}\text { Social distancing prevents spread of } \\
\text { COVID-19 }\end{array}$ & Yes & $54(100 \%)$ & $30(100 \%)$ & $33(100 \%)$ \\
\hline 14 & $\begin{array}{l}1 \% \text { hypochlorite solution is suitable for } \\
\text { sanitization in COVID-19 }\end{array}$ & No & $5(9 \%)$ & $5(17 \%)$ & $7(21 \%)$ \\
\hline 15 & $\begin{array}{l}\text { Hand wash with soap and water prevent } \\
\text { spread of COVID-19 }\end{array}$ & Yes & $54(100 \%)$ & $30(100 \%)$ & $33(100 \%)$ \\
\hline 16 & Wearing mask prevent spread of COVID-19 & Yes & $54(100 \%)$ & $30(100 \%)$ & $33(100 \%)$ \\
\hline 17 & $\begin{array}{l}\text { Your awareness of bio medical waste is } \\
\text { adequate }\end{array}$ & No & $7(13 \%)$ & (0)100\% & $4(12 \%)$ \\
\hline 18 & Discarded PPE should go in yellow bag & Yes & $54(100 \%)$ & $30(100 \%)$ & $33(100 \%)$ \\
\hline
\end{tabular}

Although results were statistically significant for ANOVA ( $p$ $=0.008$ ) among three groups of hospital staffs for knowledge-based questions, residuals were not normally distributed $\left(p=3.37 \times 10^{-10}\right)$. Hence, non-parametric approach was used to examine the difference among hospital staffs. Median value for doctors (median $=18$ ) was higher in comparison to nurses (median $=17.5$ ) and technical staff (median $=17$ ). There was a statistically significant difference $(P=0.02)$ in knowledge among hospital staffs. Pairwise comparisons yielded the significant difference $(P=0.02)$ between doctors-technical staffs. There was no statistical difference between other groups. Fig 1 shows that doctors had good knowledge towards COVID-19, only 1 outlier was there.

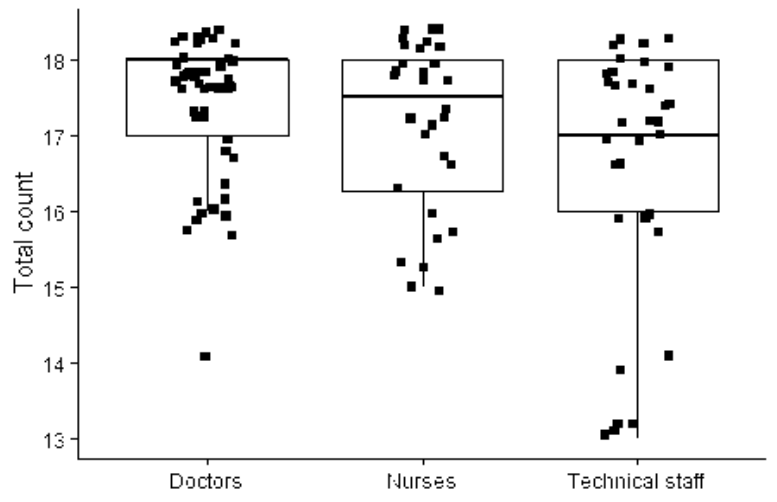

Figure 1: Box plot showing dispersion of scores for knowledge among HCWs 
All the health care workers responded to all 10 items on their attitude regarding COVID-19. Findings demonstrated highly positive attitude of health care workers towards COVID-19, 109 participants were apprehensive that they will probably get illness; only $8(6.83 \%)$ respondents were neutral. Most respondents were worried that one of their family members/friends/co-boarders may get an infection, only $12(10.25 \%)$ disagreed with this statement.
$115(98.29 \%)$ strongly agreed that they will use the vaccine against COVID-19, only $2(1.70 \%)$ denied taking vaccine against COVID-19. All the respondents agreed that mis behaviour with health care worker affects work potential and $98(83.76 \%)$ strongly agreed that managing COVID-19 pandemic is difficult without security. All questions related to attitude of health care workers towards COVID- 19 have been evaluated in Table 3.

Table3: Attitude of healthcare workers toward COVID-19 (Score 1 to 5)

\begin{tabular}{|c|c|c|c|c|c|c|}
\hline S. No & Question & $\begin{array}{c}1 \\
\text { (Strongly agree) }\end{array}$ & $\begin{array}{c}2 \\
\text { (Agree) }\end{array}$ & $\begin{array}{c}3 \\
\text { (Neutral) }\end{array}$ & $\begin{array}{c}4 \\
\text { (Disagree) }\end{array}$ & $\begin{array}{c}5 \\
\text { (Strongly disagree) }\end{array}$ \\
\hline 1 & You think you will probably get illness & $94(80.34 \%)$ & $15(12.82 \%)$ & $8(6.83 \%)$ & $0(0 \%)$ & $0(0 \%)$ \\
\hline 2 & $\begin{array}{l}\text { You are worried one of your family } \\
\text { members/friends/co-boarders may } \\
\text { get an infection }\end{array}$ & $22(18.80 \%)$ & $83(70.94 \%)$ & $0(0 \%)$ & $12(10.25 \%)$ & $0(0 \%)$ \\
\hline 3 & $\begin{array}{l}\text { If getting COVID-19, you will accept } \\
\text { isolation in health facilities }\end{array}$ & $117(100 \%)$ & $0(0 \%)$ & $0(0 \%)$ & $0(0 \%)$ & $0(0 \%)$ \\
\hline 4 & $\begin{array}{l}\text { Transmission of COVID-19 can be } \\
\text { prevented by washing hands with } \\
\text { soap frequently }\end{array}$ & $109(93.16 \%)$ & $8(6.83 \%)$ & $0(0 \%)$ & $0(0 \%)$ & $0(0 \%)$ \\
\hline 5 & $\begin{array}{l}\text { Prevalence of COVID- } 19 \text { can be } \\
\text { reduced by the active participant of } \\
\text { HCWs in hospital infection control } \\
\text { programs }\end{array}$ & $117(100 \%)$ & $0(0 \%)$ & $0(0 \%)$ & $0(0 \%)$ & $0(0 \%)$ \\
\hline 6 & $\begin{array}{l}\text { If a COVID-19 vaccine was available, I } \\
\text { would have it }\end{array}$ & $115(98.29 \%)$ & $0(0 \%)$ & $0(0 \%)$ & $2(1.70 \%)$ & $0(0 \%)$ \\
\hline 7 & $\begin{array}{l}\text { Covid-19 patients should be kept in } \\
\text { isolation }\end{array}$ & $117(100 \%)$ & $0(0 \%)$ & $0(0 \%)$ & $0(0 \%)$ & $0(0 \%)$ \\
\hline 8 & $\begin{array}{l}\text { Medical staffs are ready to } \\
\text { participate in anti-epidemic in the } \\
\text { community }\end{array}$ & $117(100 \%)$ & $0(0 \%)$ & $0(0 \%)$ & $0(0 \%)$ & $0(0 \%)$ \\
\hline 9 & $\begin{array}{l}\text { Misbehaviour with health care } \\
\text { worker affects your work potential }\end{array}$ & $102(87.17 \%)$ & $15(12.82 \%)$ & $0(0 \%)$ & $0(0 \%)$ & $0(0 \%)$ \\
\hline 10 & $\begin{array}{l}\text { Managing COVID-19 pandemic is } \\
\text { difficult without security }\end{array}$ & $98(83.76 \%)$ & $19(16.23 \%)$ & $0(0 \%)$ & $0(0 \%)$ & $0(0 \%)$ \\
\hline
\end{tabular}

Similar to knowledge-based questionnaire, ANOVA results were significant $(p=0.02)$ among three groups of hospital staffs for attitude-based questions. However, distribution of residuals failed the normality assumption $\left(p=2.94 \times 10^{-}\right.$ $\left.{ }^{6}\right)$ for attitude-based questionnaire. Hence, a nonparametric approach was used for further analysis. Doctors as expected showed higher median values ( median $=13$ ) than nurses (median $=12$ ) and technical staffs (median $=12$ ). Our result yielded a statistically significant difference $(P=0.02)$ in attitude among hospital staff. Post-hoc analysis yielded the statistically significant difference between doctors-nurse $(P=0.04)$ and doctorstechnical staff $(P=0.04)$ pair. There was no statistical difference between nurses and technical staffs. Figure 2 shows that doctors have better attitude compared with nurses and technical staff towards COVID- 19.

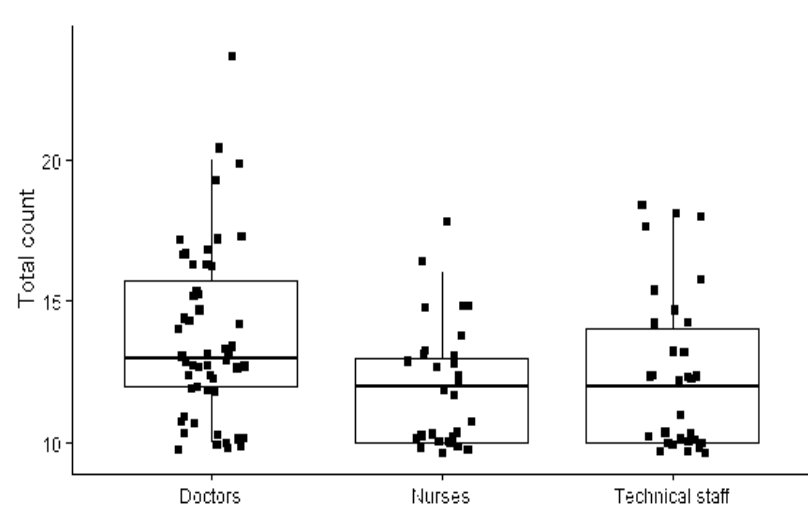

Figure 2: Box plot showing dispersion of score for attitude among HCWs.

Pearson correlation coefficient showed that among the health care workers of tertiary care hospital there was a weak positive correlation, $r(115)=.20, p=.0299$ between knowledge and attitude for COVID-19. 


\section{DISCUSSION}

Our study tried to provide the significant insight into knowledge and attitude of healthcare workers about COVID- 19. The study results showed relatively good knowledge and positive attitude towards COVID- 19 among the health care workers. We found that the knowledge and attitude was higher among doctors followed by nurses and technical staff (as in accordance to their training). On analysis of data, of the total participants, 110 were in good knowledge category and 7 had poor knowledge. 116 reported to have positive attitude and only 1 had negative attitude which were nearly similar to study conducted in Italy. ${ }^{9}$ Our study among health care workers of tertiary care hospital indicates a positive correlation between good knowledge and positive attitude with correlation value of 0.20 implying that correlation is very weak.

The study found that the majority of the respondents know that COVID- 19 is a global issue and collected their information through a variety of sources such as social media (Doctors 63\%, nurses 67\%, and technical staff 79\%) as main source of information followed by television and hospital website. Another study showed that the highest main source of collected information from seminars and workshops accounting for $48 \% .{ }^{10} \mathrm{~A}$ recent study by Giao et al 2020, showed social media as a main source of information regarding COVID-19 and was used by $91.1 \%$ participant health care workers. ${ }^{11}$ Similarly other studies have shown that the most used source of information is social media among HCWs in countries like China, and in general public of United States and United Kingdom. ${ }^{12,13}$ The most likely reason is that social media provides information quickly without censorship, but the disadvantage is that it is not reliable, unverified and of doubtful credibility. Thus, HCWs should verify the information and validate with scientific content. Our findings show that health care workers are more interested to gather knowledge from social media on an emerging infectious disease like COVID-19 than the official website of the Ministry of Health at the present time.

Health care workers possessed good knowledge of precautionary measures such as wearing gloves, washing hands with soap frequently and wearing mask and that these are effective while interacting with COVID- 19 patients was evident in the present study. Prior studies have shown that good knowledge and practice of health care workers in complying safety measures creates awareness among patients, as well as gives an important message to the society. ${ }^{14}$ The present study showed that all the HCWs of this institute are following infection prevention and control practices as recommended by the Ministry of Health India and WHO. Because of novelty of COVID- 19 and uncertain pathology and epidemiology these measures become crucial for preventing its transmission. Our result is comparable to studies done during previous epidemics where these personal preventive behaviors were seen in 95.4 and $85.7 \%$ of health care workers. ${ }^{15,16}$

In this study, the doctors and nursing staff had better score of knowledge and attitude regarding COVID-19 than technical staff (laboratory technicians). Similar findings were found in a study conducted globally by web-based survey in March 2020 which reported that doctors had better knowledge as compared to pharmacists. ${ }^{17}$ In contrast, Saqlain et al. in a study from Pakistan found that pharmacists had greater knowledge than doctors and nurses. ${ }^{18}$ This can be attributed to the fact that doctors and nursing staff had attended the training program on safe practices during COVID- 19 being imparted to HCWs earlier whereas training of laboratory technicians started few weeks after training of doctors and nurses in our institute. Previous studies have revealed that training by hospitals play a pivotal role in prevention of infectious disease ${ }^{19}$ and that appropriate education of protective measures improve the HCWs willingness to work. ${ }^{20}$ This further reiterates that training of $\mathrm{HCWs}$ through continuous professional education and predominantly on symptoms and transmission are essential in improving the knowledge of health care workers about COVID-19 in a tertiary care centre.

In our study, $21 \%$ health care workers had incorrect knowledge that antibiotics are the first-line treatment in COVID- 19 patients and the question that patients with underlying chronic diseases are at a higher risk of infection, doctors possessed good knowledge and $20 \%$ nurses and $27 \%$ technical staff answered incorrectly. Since many antibiotics have been repurposed for the management of COVID-19 in the absence of definitive treatment and lack of vaccine, this could have led to erroneous knowledge and misunderstanding among HCWs. Therefore, there is urgent need to impart adequate training regarding treatment of COVID- 19 patients through multiple training programs, particularly among doctors.

Responding to the question whether family members of COVID-19 patients should be isolated, incorrect answer was given by the $15 \%$ doctors, $20 \%$ nurses and $24 \%$ technical staff asking for isolation. This view has been invalidated by the study of $P$. Ramachandran which suggests that family member need only to be quarantined. ${ }^{21}$ The question whether $1 \%$ hypochlorite solution is suitable for sanitization in COVID-19, $9 \%$ doctors, $17 \%$ nurses and $21 \%$ technical staff had insufficient knowledge about solutions used for sanitization in COVID- 19 disease and rest responded that $1 \%$ hypochlorite solution is suitable for sanitization in COVID- $19 .{ }^{22}$

Present study has revealed a lack of knowledge as regard biomedical waste management among $13 \%$ doctors and $12 \%$ technical staff though nurses were adequately trained and were aware about hand hygiene and biomedical waste management. Since, biomedical waste management is vital to prevent the spread of COVID- 19 among health care 
workers and community there is urgent need to stress on its management during ongoing in-house trainings.

Our results suggest that majority of health care workers in this study had positive attitude. Though, more than $80 \%$ contemplated that they will probably get illness and more than $85 \%$ were worried that one of their family members/friends/co-boarders might get infection. In our study $100 \%$ had positive attitude that transmission of COVID-19 can be prevented by washing hands with soap frequently. Proper safety precautions as well as adequate provision of personal protective equipment (PPE) will ensure more effective services to the needy. A disturbing aspect evolved out of study was that most health care workers agreed that the misbehaviour with health care workers affects their work potential; as sporadic events of misbehaviour with doctors were reported in India. ${ }^{23}$ These events demoralize HCWs and may affect their work potential and determination to fight against COVID- 19 disease. This was reflected in their response health care workers $(100 \%)$ that managing COVID-19 pandemic is difficult without security.

One of the weaknesses of our study was that not all the health care workers of our institute could be included in the study as they were either performing shift duties or were in isolation as per protocol after their duties so the result of our study could not be generalised. Another limitation is that it was a questionnaire-based study, the responses are self-reported and tests the recall ability of participants and thus detailed interview could elicit knowledge and attitude of respondent in a better way. Since, the sample size of the study was small and convenient sampling was done, so the findings of the study could not be generalized.

\section{CONCLUSION}

The finding of this study showed that health care workers in tertiary care hospital have good knowledge and positive attitude regarding COVID-19. The study highlights gaps in specific aspects of knowledge and attitude that should be focused in future awareness and educational programs. Promotion of preventive measures against COVID-19 and training in clinical knowledge regarding COVID- 19 is essential to prevent lethal effects of pandemic COVID- 19. Further large sample of HCWs could be studied for better assessment of knowledge and attitude, so as to formulate guidelines for appropriate training and management during pandemics. It is therefore recommended that health authorities invest in training health care workers for disease outbreak response, as their preparedness is essential for reducing disease transmission and better management of patients. Our result with further allow to develop more in-depth research of knowledge and attitude of health care workers in India.

Acknowledgement: We acknowledge the contribution of healthcare workers who participated in this study for their cooperation and support.

\section{REFERENCES}

1. WHO2020. Coronavirus. Available at: www.who.int/health-topics/coronavirus [Accessed on: 2021 May 2].

2. Lei S, Jiang F, Su W, Chen C, Chen J, Mei W, et al. Clinical characteristics and outcomes of patients undergoing surgeries during the incubation period of COVID-19 infection. EClinical Medicine. 2020; 21: 100331. DOI:10.1016/j.eclinm.2020.100331

3. Bhagavathula AS, Aldhaleei WA, Rahmani J, Mahabadi MA, Bandari DK. Knowledge and perceptions of COVID-19 among health care workers: cross-sectional study. JMIR Public Health Surveill. 2020; 6(2): e19160. doi: 10.2196/19160. PMID: 32320381

4. Gan WH, Lim JW, Koh D. Preventing intra-hospital infection and transmission of coronavirus disease 2019 in healthcare workers. Saf Health Work. 2020; 11(2): 241-243. DOI: 10.1016/j.shaw.2020.03.001.

5. Nemati M, Ebrahimi B, Nemati F. Assessment of Iranian nurses' knowledge and anxiety toward COVID-19 during the current outbreak in Iran. Arch Clin Infect Dis. 2020; 15(COVID-19): e102848. DOI: https://doi.org/10.5812/archcid.102848.

6. Omrani AS, Shalhoub S. Middle East respiratory syndrome coronavirus (MERS-CoV): what lessons can we learn? J Hosp Infect. 2015; 91(3): 188-96.

7. Khan MU, Shah S, Ahmad A, Fatokun O. Knowledge and attitude of healthcare workers about middle east respiratory syndrome in multispecialty hospitals of Qassim, Saudi Arabia. BMC Public Health. 2014; 14: 1281.

8. Nour MO, Babilghith AO, Natto HA, Al-Amin FO, Alawneh SM. Knowledge, attitude and practices of healthcare providers towards MERS-CoV infection at Makkah hospitals, KSA. Int Res J Med Med Sci. 2015; 3(4): 103-112.

9. Moro M, Vigezzi GP, Capraro M, Biancardi A, Nizzero P, Signorelli C, et al. 2019-novel coronavirus survey: knowledge and attitudes of hospital staff of a large Italian teaching hospital. Acta Bio-medica: 2020; 91(3-S): 2934.DOI: 10.23750/abm.v91i3-s.9419.

10. Albarrak Al, Mohammed R, Al Elayan A, Al Fawaz F, Al Masry M, Al Shammari M, et al. Middle East Respiratory Syndrome (MERS): Comparing the knowledge, attitude and practices of different health care workers. J Infect Public Health 2021; 14(1): 89-96. DOI: https://doi.org/10.1016/j.jiph.2019.06.029.

11. Huynh G, Nguyen TNH, Tran VK, Vo KN, Vo VT, Pham LA. Knowledge and attitude toward COVID-19 among healthcare workers at District 2 Hospital, Ho Chi Minh City. Asian Pac J Trop Med 2020; 13(6): 260-265.

12. Shi $Y$, Wang J, Yang $Y$, Wang $Z$, Wang $G$, Hashimoto $K$, et al. Knowledge and attitude of medical staff in Chinese psychiatric hospital regarding COVID 19. Brain Behav Immun Health, 2020; 4: 100064 doi: 10.1016/j.bbih.2020.100064.

13. Geldsetzer P. Knowledge and perceptions of covid-19 among the general public in the United States and the United Kingdom: a cross-sectional online survey. Ann 
Intern Med. 2020; 173(2): 157-160. DOI: 10.7326/M200912.

14. Zhong BL, Luo W, Li HM, Zhang QQ, Liu XG, Li WT, et al. Knowledge, attitudes, and practices towards COVID-19 among Chinese residents during the rapid rise period of the COVID-19 outbreak: a quick online cross-sectional survey. Int J Biol Sci. 2020; 16(10): 1745-1752. DOI: https://doi.org/10.7150/ijbs.45221.

15. Abolfotouh MA, Al-Qarni AA, Al-Ghamdi SM, Salam M, AlAssiri $\mathrm{MH}$, Balkhy $\mathrm{HH}$. An assessment of the level of concern among hospital-based health-care workers regarding MERS outbreaks in Saudi Arabia. BMC Infect Dis 2017; 17: 4

16. Khan MU, Shah S, Ahmad A, Fatokun O. Knowledge and attitude of healthcare workers about middle east respiratory syndrome in multispecialty hospitals of Qassim, Saudi Arabia. BMC Public Health. 2014; 14: 1281.

17. Bhagavathula AS, Aldhaleei WA, Rahmani J, Mahabadi MA, Bandari DK. Novel coronavirus (COVID-19) knowledge and perceptions: a survey on healthcare workers. MedRxiv 2020. https://doi.org/10.1101/2020.03.09.20033381.

18. Saqlain M, Munir MM, Rehman SU. Knowledge, attitude, practice and perceived barriers among healthcare professionals regarding COVID-19: a Cross-sectional survey from Pakistan. J Hosp Infect. 2020; 105(3): 419-423. DOI:10.1016/j.jhin.2020.05.007.

19. Anuradha $\mathrm{M}$, Dandekar RH. Knowledge, Attitude and Practice among food handlers on food borne diseases: a hospitalbased study in tertiary care hospital. Int J Biomed Adv Res 2014; 5 (4): 196-198

20. Stergachis A, Garberson L, Lien O, D’Ambrosio L, Sangaré L, Dold C. Health care workers' ability and willingness to report to work during public health emergencies. Disaster Med Public Health Prep. 2011; 5 (4): 300-308

21. Ramachandran P, Kalaivani K. Health System Response to COVID-19 Epidemic in India. Ann Natl Acad Med Sci (India). 2020; 56(2): 67-76. DOI: 10.1055/s-0040-1713347

22. Roy A, Parida SP, Bhatia V. Role of disinfection and hand hygiene: a COVID-19 perspective. Int J Community Med Public Health. 2020; 7(7): 2845.

Pandey V.Coronavirus: India doctors 'spat at and attacked' BBC News Delhi. Available at: https://www.bbc.com/news/world-asia-india-52151141 [Accessed on 2021April 03]

Source of Support: The author(s) received no financial support for the research, authorship, and/or publication of this article.

Conflict of Interest: The author(s) declared no potential conflicts of interest with respect to the research, authorship, and/or publication of this article.

For any question relates to this article, please reach us at: editor@globalresearchonline.net New manuscripts for publication can be submitted at: submit@globalresearchonline.net and submit_ijpsrr@rediffmail.com 